\title{
Teor proteico e mineral das silagens de sorgo consorciadas com gramíneas aditivadas com ureia
}

\author{
Cruz, S.S. ${ }^{\circledR}$; Pascoaloto, I.M. ${ }^{2}$; Andreotti, M. ${ }^{3}$; Lima, G.C. ${ }^{3}$; Lattari, J.V.F. ${ }^{3}$; Soares, D. A. ${ }^{3}$; Morais, G.N. ${ }^{3}$ e Dickmann, L. ${ }^{3}$
}

'Instituto Federal do Pará, campus de Marabá. Brasil.

2Departamento de Produção e Melhoramento Vegetal. Universidade Estadual Paulista, UNESP, campus de Botucatu. Brasil.

3Departamento de Fitossanidade, Engenharia Rural e Solos. UNESP, campus de llha Solteira. Brasil.

\section{PALAVRAS CHAVE ADICIONAIS}

Consórcio.

Megathyrsus maximus.

Urochloa brizantha.

\section{RESUMO}

O conhecimento da dinâmica de cultivo do sorgo consorciado com forrageiras tropicais para produção de silagem é importante tanto para a nutrição animal, visando a qualidade do alimento, como para a sustentabilidade do sistema de produção agrícola. Seguindo essa lógica, o objetivo desta pesquisa foi avaliar os teores de proteína bruta e de macronutrientes das silagens de sorgo forrageiro em cultivo solteiro ou em consórcio com capim-marandu ou capim-mombaça, acrescidas de doses de ureia no momento da ensilagem. $O$ delineamento experimental foi de blocos ao acaso, em fatorial $3 \times 5$, com os três tipos de silagem (sorgo forrageiro em monocultivo, consorciado com Urochloa brizantha cv. Marandu ou com o Megathyrsus maximus cv. Mombaça) e cinco doses de ureia como aditivo na ensilagem ( 0 ; $2,5 ; 5,0$ e $7,5 \%)$. Foram determinados os teores de proteína bruta e de macronutrientes $(P$, $\mathrm{K}, \mathrm{Ca}, \mathrm{Mg}$ e S) antes e após o processo de ensilagem. A adição de doses até 7,5\% de ureia no material a ser ensilado é eficiente em aumentar o teor de proteína bruta e de enxofre da silagem. As silagens de sorgo forrageiro consorciado com capim-marandu e capim-mombaça apresentaram maiores teores de proteína bruta, fósforo e potássio que a silagem de sorgo em monocultivo quando não há adição de ureia.

\section{Protein and mineral content in sorghum silage with grasses and urea}

\section{SUMMARY}

Knowing cultivation dynamics of sorghum intercropped with tropical forage for silage production is important both for animal nutrition and for the quality of the food, as well as for the sustainability of the agricultural production system. Following this logic, the objective of this research was to evaluate the gross protein and macronutrient contents of sorghum silages in consortium with marandu grass or mombaça grass with increasing doses of urea. The experimental design was a $3 \times 5$ factorial randomized block design with three types of silage (forage sorghum in monoculture and forage sorghum in consortium with Urochloa brizantha cv. Marandu or with Megathyrsus maximus cv. Mombaça) and five urea doses as silage additive $(0,2.5,5.0$ and $7.5 \%)$. The levels of crude protein and macronutrients $(P, K$, $\mathrm{Ca}, \mathrm{Mg}$ and S) were determined before and after the ensiling process. The higher the urea dose used the higher the crude protein content. The addition of urea may result in lower $\mathrm{Ca}$ and $\mathrm{S}$ losses and higher Mg losses during the ensiling process.

\section{INTRODUÇÃO}

O clima Aw da classificação de Koppen-Geiger representa cerca de $11,5 \%$ da superfície terrestre e é o segundo tipo mais comum (Peel et al. 2007). De acordo com Alvares et al. (2013), o clima Aw é caracterizado por baixa disponibilidade hídrica durante pelo menos um mês do ano, com precipitações abaixo de $60 \mathrm{~mm}$, e no Cerrado brasileiro e na Savana africana apresenta invernos secos e verões chuvosos e quentes.

A diferença na temperatura e na quantidade de água disponível durante o inverno nessas regiões limita a produção animal pelo menor crescimento da forragem verde e consequente escassez de alimento, o que resulta em menor ganho de peso animal e aumento no período de abate. Uma alternativa para evitar esse 
problema é a conservação de forragem na forma de silagem, o que permite a utilização do excedente de forrageiras produzido nas épocas chuvosas e reduz os efeitos negativos do período crítico sobre a produção pecuária (Ribeiro et al. 2010). Entretanto, o uso de silagem na produção animal não é somente por conta da escassez de alimentos, mas em sistemas mais tecnificados (semi-confinamentos, confinamentos) o uso da silagem se torna uma opção de alimentação de qualidade para os animais.

Dentro das caraterísticas climáticas dessa região uma opção viável é a produção de silagem de sorgo forrageiro consorciado com gramíneas do gênero Urochloa ou Megathyrsus (Fernandes et al. 2009), pela rusticidade e adaptação dessas espécies a solos tropicais, em geral ácidos e com baixa fertilidade, e a altas temperaturas e baixos índices pluviométricos (Getachew et al. 2016). A produção de silagens de gramíneas tropicais, no entanto, apresentam baixo teor de proteína, constituindo assim uma limitação ao seu uso, principalmente para animais de alta exigência nutricional. Uma alternativa para melhorar o valor nutritivo do material ensilado é a inclusão de produtos com maiores teores proteicos (Vilela, 2008).

Entretanto, ensilar forrageiras com alto teor de umidade pode resultar no desenvolvimento de microrganismos indesejáveis que degradam proteínas e levam à perda de nutrientes por efluentes e gases (Oliveira et al. 2009). A ureia é um aditivo químico da classe dos nutrientes, pois quando adicionada à silagem promove elevação do teor de proteína bruta, promovendo aumento da estabilidade aeróbia devido à ação antifúngica da amônia. Como também a ureia é capaz de diminuir as perdas de MS e de açúcares solúveis do material (Nussio \& Santos 2006).

Embora existam diversos trabalhos demonstrando o efeito benéfico da utilização de ureia sobre a qualidade bromatológica da silagem, como teores de fibra e digestibilidade do alimento (Carvalho et al. 2006; Oliveira et al. 2009; Pires et al. 2003 2004; Reis et al. 2001 a,b; Ribeiro et al. 2010; Silva et al. 2014; Zambom et al. 2014), há escassez na literatura de estudos que demonstrem a influência desse aditivo sobre os teores de nutrientes na silagem após o processo de fermentação.

Por isso, o presente trabalho teve como objetivo avaliar os teores de proteína bruta e de macronutrientes $(\mathrm{P}, \mathrm{K}, \mathrm{Ca}, \mathrm{Mg}$ e $\mathrm{S})$ presentes nas silagens de sorgo forrageiro em cultivo solteiro e em consórcio com as gramíneas Urochloa brizantha cv. Marandu ou Megathyrsus maximus cv. Mombaça, acrescidas de doses de ureia no momento da ensilagem.

\section{MATERIAL E MÉTODOS}

O experimento foi conduzido em área não irrigada da Fazenda de Ensino, Pesquisa e Extensão (FEPE) - Setor de Produção Vegetal da Faculdade de Engenharia de Ilha Solteira (FE/UNESP), São Paulo, Brasil. O clima é Aw segundo a classificação de Koppen, caracterizado como tropical úmido com estação chuvosa no verão e seca no inverno. Os dados referentes à precipitação pluvial e temperaturas máxima, mínima e média (Figura 1) foram registrados diariamente na estação meteorológica automática instalada a $500 \mathrm{~m}$ da área experimental.

De acordo com a classificação brasileira, o solo da área experimental é Latossolo Vermelho distrófico típico argiloso (Embrapa, 2013). Com o objetivo de caracterizar o solo antes da implantação do experimento, efetuou-se análise química, segundo metodologia proposta por Raij et al. (2001), sendo encontrados os valores apresentados na Tabela I.

O delineamento experimental foi em blocos casualizados, em esquema fatorial 3 x 5, com oito repetições. Os tratamentos foram três tipos de silagem (sorgo forrageiro - Sorghum bicolor - cv. Volumax em solteiro, consorciado com Urochloa brizantha cv. Marandu ou com o Megathyrsus maximus cv. Mombaça) e cinco doses de ureia como aditivo na ensilagem $(0 ; 2,5 ; 5,0$ e $7,5 \%$ ). As parcelas foram constituídas por 7 linhas de sorgo espaçadas a 0,45 m e $20 \mathrm{~m}$ de comprimento, perfazendo $63 \mathrm{~m}^{2}$. A área útil da parcela foi delimitada pelas 3 linhas centrais.

O sorgo foi semeado mecanicamente no dia 04 de novembro de 2014 por meio de semeadora-adubadora com mecanismo sulcador tipo haste (facão) para plantio direto, a uma profundidade de aproximadamente 0,03 m, com 15 sementes por metro linear. Momentos antes da semeadura, as sementes das forrageiras foram misturadas ao fertilizante e depositados no compartimento de adubos da semeadora, visando a deposição em profundidade maior que das sementes de sorgo, com intuito de retardar a emergência e diminuir a competição entre as espécies no período inicial de desenvolvimento. Foram utilizados $9,6 \mathrm{~kg} \mathrm{ha}^{-1}$ de sementes de capim-marandu (VC $=50 \%$ ) e 10,3 $\mathrm{kg} \mathrm{ha}^{-1}$ de sementes de capim-mombaça ( VC $=35 \%)$.

Para adubação em semeadura foi utilizado $300 \mathrm{~kg}$ ha $^{-1}$ do formulado 08-28-16, e para a adubação de cobertura aplicou-se $120 \mathrm{~kg} \mathrm{ha}^{-1}$ de $\mathrm{N}$ na forma de sulfato de amônio e $50 \mathrm{~kg} \mathrm{ha}^{-1}$ de $\mathrm{K}_{2} \mathrm{O}$ na forma de cloreto de potássio. Essas aplicações foram feitas no momento em que as plantas do sorgo apresentavam 6 folhas

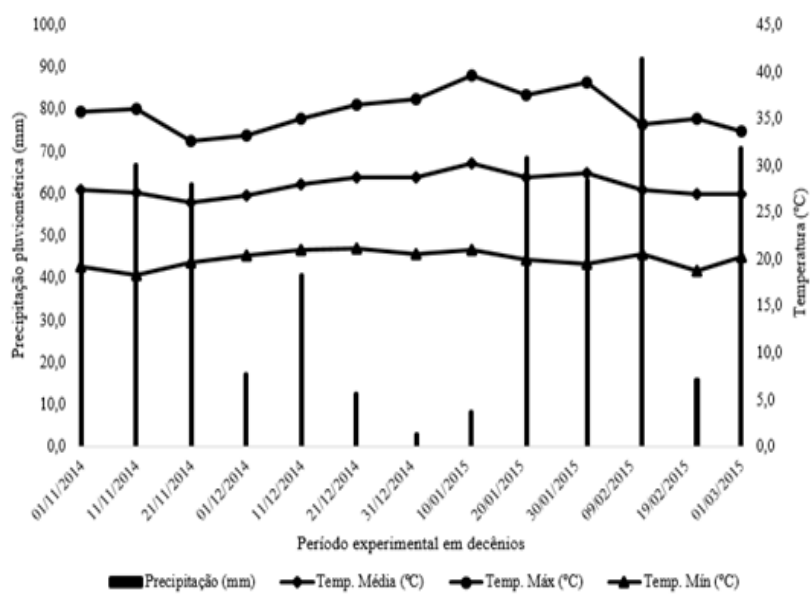

Figura 1. Dados climáticos do período experimental, coletados na estação meteorologica da FEPE. Selvíria, MS (Climatic data from the experimental period, collected at the FEPE meteorological station. Selvíria, MS). 
Tabela I. Caracterização química inicial do solo nas profundidades de 0 a 0,10 m e de 0,10 a 0,20 m na área experimental (Initial chemical characterization of soil in the depths from 0 to $0.10 \mathrm{~m}$ and from 0.10 to $0.20 \mathrm{~m}$ in the experimental área).

\begin{tabular}{|c|c|c|c|c|c|c|c|c|}
\hline \multirow{2}{*}{ Profundidade } & \multirow{2}{*}{$\mathrm{pH}\left(\mathrm{CaCl}_{2}\right)$} & \multirow{2}{*}{$\begin{array}{c}\mathrm{P} \\
\left(\mathrm{mg} \mathrm{dm}^{-3}\right)\end{array}$} & $\mathrm{K}$ & $\mathrm{Ca}$ & $\mathrm{Mg}$ & $\mathrm{H}+\mathrm{Al}$ & \multirow{2}{*}{$V(\%)$} & \multirow{2}{*}{$\begin{array}{c}\mathrm{MO} \\
\left(\mathrm{g} \mathrm{dm}^{-3}\right)\end{array}$} \\
\hline & & & \multicolumn{4}{|c|}{$\left(\mathrm{mmol}_{\mathrm{c}} \mathrm{dm}^{-3}\right)$} & & \\
\hline $0,00-0,10 \mathrm{~m}$ & 4,8 & 62,0 & 1,6 & 12,0 & 10,0 & 38 & 38,0 & 21,0 \\
\hline $0,10-0,20 \mathrm{~m}$ & 4,4 & 17,0 & 1,0 & 7,0 & 6,0 & 47 & 23,0 & 16,0 \\
\hline
\end{tabular}

desenvolvidas, conforme recomendado por Cantarella et al. (1997).

O corte para a produção da silagem, foi realizado mecanicamente a 0,30 m do nível do solo, aos 124 dias após a semeadura, quando os grãos do sorgo se apresentavam no estádio farináceo, com colhedora de forragem modelo JF C-120 (12 facas), sendo o material picado em partículas médias de $0,025 \mathrm{~m}$.

A ureia em forma granulada, foi adicionada no momento da ensilagem, de acordo às respectivas doses para cada tratamento. As silagens foram confeccionadas em silos de PVC (0,5 x 0,1 m). A compactação da massa ensilada $\left(600 \mathrm{~kg} \mathrm{~m}^{-3}\right)$, foi realizada com prensa hidráulica manual, com capacidade de pressão de até 15 toneladas. Após o enchimento dos silos experimentais, estes foram hermeticamente fechados com fitas adesivas, afim de evitar a ocorrência de fermentação aeróbia, e a abertura dos mesmos ocorreu após 30 dias.

Do material vegetal colhido em campo e do fermentado no silo foram retiradas sub amostras de $300 \mathrm{~g}$, adequadamente acondicionadas e colocadas em estufa com circulação forçada a ar a $65^{\circ} \mathrm{C}$, por $72 \mathrm{~h}$, pesadas para o cálculo da matéria seca (MS), e trituradas em moinho tipo "Willey" (peneira com crivos de $1 \mathrm{~mm}$ ) para análise laboratorial. O teor de proteína bruta (PB) foi determinado pela multiplicação do teor de nitrogênio total, mensurado pelo método micro-Kjehldal, por 6,25, segundo metodologia proposta por Silva e Queiroz (2002) e os teores de macronutrientes foram determinados segundo metodologia proposta por Malavolta et al. (1997).

Os resultados foram submetidos à análise de variância pelo teste $\mathrm{F}$, sendo as médias dos atributos avaliados das silagens comparadas pelo teste Tukey a $5 \%$ de probabilidade. As doses de ureia foram submetidos à análise de regressão e, para escolha do melhor modelo, considerou-se significância de $5 \%$ para os coeficientes adjuntos das equações e os maiores valo- res dos coeficientes de determinação, utilizando-se do software SISVAR (Ferreira, 2014).

\section{RESULTADOS E DISCUSSÃO}

Observa-se que o tratamento com sorgo solteiro foi o que apresentou maior teor de MS (Tabela II), seguido do sorgo consorciado com capim-mombaça e capim-marandu. Segundo CARVALHO et al (1992), o teor de matéria seca da planta forrageira é um dos fatores determinantes do tipo de fermentação no processo da ensilagem e pode variar em função da idade de corte e também da natureza do colmo da planta. Quando os teores de MS estão acima de $25 \%$, e associados a um bom nível de carboidratos solúveis são suficientes para produção de uma silagem de boa qualidade (McDonald et al. 1991). Ítavo et al. (2010), estudando a composição química e parâmetros fermentativos de silagens de capim-elefante e cana-de-açúcar tratadas com aditivos, verificou teores de matéria seca entre 26,9 a $44,6 \%$ de MS no material antes da ensilagem, para o autor os valores de MS dos tratamentos avaliados são considerados ideais para confecção de silagens de boa qualidade por proporcionarem facilidade na compactação da massa a ser ensilada, o que pode se refletir na redução das perdas durante a ensilagem.

O consórcio de sorgo com capim-mombaça foi o que proporcionou material vegetal a ser ensilado com maiores teores de proteína bruta, P, Ca, Mg e S, enquanto que os maiores teores de $\mathrm{K}$ foram constatados no material proveniente do consórcio com capim-marandu (Tabela II). Com exceção do cálcio, o tratamento de sorgo solteiro apresentou menores teores para todos os demais macronutrientes, indicando que a presença de um capim na massa a ser ensilada é importante fonte de nutrientes na dieta animal. O metabolismo mineral em ruminantes envolve grande complexidade de interações entre vários macro e micronutrientes (Underwood \& Suttle 2001). Deficiências em um ou mais desses elementos podem resultar em desordens

Tabela II. Teores de matéria seca (MS), proteína bruta (PB), fósforo (P), potássio (K), cálcio (Ca), magnésio $(\mathrm{Mg})$ e enxofre $(\mathrm{S})$ do material vegetal no momento da ensilagem de sorgo e seus consórcios (Contents of dry matter (DM), Crude protein (CP), phosphorus $(\mathrm{P})$, potassium $(\mathrm{K})$, calcium $(\mathrm{Ca})$, magnesium $(\mathrm{Mg})$ and sulfur $(\mathrm{S})$ of the plant material at the time of sorghum silage and its consortia).

\begin{tabular}{|c|c|c|c|c|c|c|c|}
\hline \multirow{2}{*}{ Tipos de silagem } & MS & PB & $P$ & K & $\mathrm{Ca}$ & $\mathrm{Mg}$ & $S$ \\
\hline & $\%$ & \multicolumn{6}{|c|}{--_--_e- } \\
\hline Sorgo/U. brizantha & 36,71 & 5,42 & 0,17 & 0,60 & 0,26 & 0,25 & 0,14 \\
\hline Sorgo/M. maximum & 37,45 & 5,64 & 0,20 & 0,53 & 0,29 & 0,44 & 0,17 \\
\hline Sorgo solteiro & 37,85 & 5,42 & 0,15 & 0,40 & 0,25 & 0,27 & 0,13 \\
\hline Médias & 37,33 & 5,49 & 0,17 & 0,51 & 0,27 & 0,32 & 0,15 \\
\hline CV $(\%)$ & 2,37 & 3,43 & 15,40 & 13,04 & 14,83 & 17,42 & 28,53 \\
\hline
\end{tabular}


Tabela III. Teores médios, significância e modelos de regressão linear ou quadrática entre tipos de silagem e doses de ureia para materia seca e teores de proteína bruta (PB) (Mean levels, significance and models of linear or quadratic regression between silage types and urea doses for dry matter and crude protein (PB) levels).

\begin{tabular}{|c|c|c|c|c|}
\hline \multirow{2}{*}{ Tipos de silagem } & \multicolumn{4}{|c|}{ Doses (\%MS) } \\
\hline & 0 & 2,5 & 5 & 7,5 \\
\hline \multicolumn{5}{|l|}{ MS (\%) } \\
\hline Sorgo/U. brizantha & $34,12 \mathrm{bC}$ & 37,66 aA & $35,36 \mathrm{cB}$ & 37,31 aA \\
\hline Sorgo/M. maximum & $35,64 \mathrm{aB}$ & $37,78 \mathrm{aA}$ & 38,46 aA & $35,81 \mathrm{bB}$ \\
\hline Sorgo solteiro & $35,04 \mathrm{aC}$ & 37,66 aA & $37,61 \mathrm{bAB}$ & $36,97 \mathrm{aB}$ \\
\hline \multicolumn{5}{|l|}{ P-Valor } \\
\hline $\mathrm{L}$ & 0,001 & 0,978 & 0,000 & 0,183 \\
\hline$Q$ & 0,000 & 0,567 & 0,000 & 0,000 \\
\hline Eq. de regressão ${ }^{1}$ & $34,0144+0,4600$ sil & 37,7078-0,0033sil & $34,8944+1,1250$ sil & $37,0322-0,1683$ sil \\
\hline $\mathrm{R}^{2}$ & 36,39 & 0,22 & 49,50 & 4,60 \\
\hline \multicolumn{5}{|l|}{ PB (\%) } \\
\hline Sorgo/U. brizantha & $5,63 \mathrm{D}$ & $13,40 \mathrm{aC}$ & $18,77 \mathrm{aB}$ & $20,60 \mathrm{aA}$ \\
\hline Sorgo/M. maximum & $5,53 \mathrm{D}$ & $10,33 \mathrm{bC}$ & $14,07 \mathrm{cA}$ & $12,17 \mathrm{cB}$ \\
\hline Sorgo solteiro & $5,03 \mathrm{C}$ & $12,20 \mathrm{aB}$ & $16,30 \mathrm{bA}$ & $17,37 \mathrm{bA}$ \\
\hline \multicolumn{5}{|l|}{ P-Valor } \\
\hline L & 0,404 & 0,004 & 0,001 & 0,000 \\
\hline Q & 0,499 & 0,000 & 0,000 & 0,000 \\
\hline Eq. de regressão ${ }^{1}$ & $4,9000+0,2500$ sil & 13,8444-0,9333sil & 18,6111-1,1167sil & 21,9111-2,6000sil \\
\hline $\mathrm{R}^{2}$ & 60,48 & 36,48 & 22,56 & 37,34 \\
\hline
\end{tabular}

Médias seguidas por diferentes letras na vertical minúscula, e letras maiúsculas na horizontal diferem entre si $(P \leq 0,05)$. ${ }^{1}$ Sugere-se equação de maior grau ou não linear. $L$ = Equação linear. $Q$ = Equação quadrática.

nutricionais sérias, ocasionando desempenho produtivo e reprodutivo aquém de seu potencial (Leonel et al. 2006).

Não foi verificado efeito ( $p>0,05)$ nas silagens sem adição de ureia, para o teor de PB (Tabela III). As silagens de sorgo consorciado com capim-marandu e de sorgo solteiro resultaram em aumentos lineares de PB em função da amonização, sendo atribuído aumento de $368 \%$ para silagem de sorgo consorciado com capim-marandu e 345\% para silagens de sorgo solteiro, quando acrescidas com 7,5\% de ureia.

A adição de ureia na silagem de sorgo consorciado com o capim-mombaça, por efeito quadrático $(\mathrm{p}<0,01)$, proporcionou maior teor de PB (14,10\%) com 5,0\% de ureia, ou seja, incremento de $254,97 \%$ em relação à não adição de ureia. Tal resultado indica menor efeito da adição de $\mathrm{N}$ mineral em silagens com forrageiras do gênero Megathyrsus, em relação às silagens sem forrageiras ou em consórcio com Urochloa.

Rylei (1967) já relatava que os teores de proteína bruta podem ser superestimados na silagem quando há adição de ureia, pois parte do $\mathrm{N}$ não proteico proveniente da ureia residual pode ser recuperado nas análises laboratoriais. Assim, nesta mesma linha de pesquisa, Carvalho et al. (2006); Fernandes, et al. (2009) e Oliveira et al. (2009) também verificaram o aumento nos teores de proteína bruta com adição de ureia na silagem. Segundo Schmidt et al. (2003), o aumento da proteína bruta se dá pela atividade ureolítica, res- ponsável pela transformação da ureia em amônia e à consequente retenção do nitrogênio na massa vegetal.

Independente da dose de ureia utilizada, observou-se que a silagem de sorgo consorciada com capim-marandu ou capim-mombaça, apresentou maiores teores proteicos em comparação às silagens de sorgo solteiro, comprovando a possibilidade de aumentar os teores de proteína da silagem quando em consórcio das duas espécies.

Foi demonstrado na análise de regressão que a adição da ureia não proporcionou incrementos nos teores de fósforo na silagem de sorgo e potássio na silagem exclusiva (Tabela IV).

A adição de $2,5 \%$ de ureia proporcionou o maior teor de fósforo $(0,19 \%)$ na silagem. Enquanto que, na silagem de sorgo solteiro, doses de 5,0 e 7,5\% de resultaram em menor teor de P. Segundo Fernandes et al. (2009), a amônia liberada pela hidrólise da ureia pode reduzir as perdas de nutrientes pela alteração no perfil fermentativo da silagem.

Com relação ao potássio (Tabela IV), o teor mínimo foi observado para a silagem de sorgo solteiro $(0,40 \%)$ em todas as doses de ureia avaliadas, e na silagem de sorgo com capim-mombaça $(0,40 \%)$ nas doses de 2,5 e $5,0 \%$ de ureia, enquanto que a silagem de sorgo consorciada com o capim-marandu, apresentou o maior teor de potássio $(0,70 \%)$. Tais resultados demonstram que há menores perdas de $\mathrm{P}$ e $\mathrm{K}$ durante o processo de fermentação quando há a presença dos capins na massa vegetal e que dentre os capins, o capim-marandu é o 
Tabela IV. Teores médios, significância e modelos de regressão linear ou quadrática entre tipos de silagem e doses de ureia para teores de fósforo $(\mathrm{P})$ e potássio $(\mathrm{K})$ (Teores médios, significância e modelos de regressão linear ou quadrática entre tipos de silagem e doses de ureia para teores de fósforo $(P)$ e potássio $(K))$.

\begin{tabular}{|c|c|c|c|c|}
\hline \multirow{2}{*}{ Tipos de silagem } & \multicolumn{4}{|c|}{ Doses (\%MS) } \\
\hline & 0 & 2,5 & 5 & 7,5 \\
\hline \multicolumn{5}{|l|}{$\mathrm{P}(\%)$} \\
\hline Sorgo/U. brizantha & $0,17 \mathrm{bB}$ & $0,19 \mathrm{aA}$ & $0,17 \mathrm{aB}$ & $0,18 \mathrm{aAB}$ \\
\hline Sorgo/M. maximum & $0,18 \mathrm{aA}$ & $0,15 \mathrm{bB}$ & $0,17 \mathrm{aA}$ & $0,17 \mathrm{aA}$ \\
\hline Sorgo solteiro & $0,15 \mathrm{cA}$ & $0,15 \mathrm{bA}$ & $0,13 \mathrm{bB}$ & $0,13 \mathrm{bB}$ \\
\hline \multicolumn{5}{|l|}{ P-Valor } \\
\hline $\mathrm{L}$ & 0,000 & 1,000 & 0,000 & 0,000 \\
\hline Q & 0,415 & 0,000 & 0,000 & 0,000 \\
\hline Eq. de regressão ${ }^{1}$ & $0,1333+0,0167 \mathrm{sil}$ & $0,1633+0,0000$ sil & $0,1156+0,0217 \mathrm{sil}$ & $0,1178+0,0217$ sil \\
\hline $\mathrm{R}^{2}$ & 100 & - & 75 & 63,69 \\
\hline \multicolumn{5}{|l|}{$\mathrm{K}(\%)$} \\
\hline SU & $0,70 \mathrm{aA}$ & $0,60 \mathrm{aB}$ & $0,60 \mathrm{aB}$ & $0,60 \mathrm{aB}$ \\
\hline SM & $0,60 \mathrm{bA}$ & $0,40 \mathrm{bC}$ & $0,40 \mathrm{bC}$ & $0,50 \mathrm{bB}$ \\
\hline SS & $0,40 \mathrm{cA}$ & $0,40 \mathrm{bA}$ & $0,40 \mathrm{bA}$ & $0,40 \mathrm{cA}$ \\
\hline \multicolumn{5}{|l|}{ P-Valor } \\
\hline $\mathrm{L}$ & 0,000 & 1,000 & 1,000 & 0,009 \\
\hline Q & 0,000 & 0,000 & 0,000 & 0,000 \\
\hline Eq. de regressão ${ }^{1}$ & 0,3667+1000sil & $0,4667+0,0000$ sil & $0,4667+0,0000$ sil & $0,4000+0,0500$ sil \\
\hline $\mathrm{R}^{2}$ & 42,86 & - & - & 25,00 \\
\hline
\end{tabular}

Médias seguidas por diferentes letras na vertical minúscula, e letras maiúsculas na horizontal diferem entre si $(P \leq 0,05)$. ${ }^{1}$ Sugere-se equação de maior grau ou não linear. $L$ = Equação linear. $Q$ = Equação quadrática.

mais eficiente em manter os teores de macronutrientes elevados.

O teor de Ca (Tabela V) obtido na silagem de sorgo solteiro aumentou $25,9 \%$ quando foi acrescido $7,5 \%$ de ureia em relação à silagem de sorgo solteiro sem aditivo.

O cálcio e o fósforo são os dois minerais requeridos em maior quantidade pelo organismo animal (NRC, 2001), entretanto, é necessário atentar para a proporção de cada elemento na silagem. Andriguetto e Perly (1990) recomendaram na dieta de animais em crescimento, alimentos com relação Ca:P de 2:1, para que não haja mobilização do cálcio dos ossos pelo organismo do animal para suprir a necessidade do elemento no caso de excesso de P. No referido experimento verifica-se que as silagens de sorgo com capim-mombaça e de sorgo solteiro acrescida de 2,5; 5,0 e 7,5\% de ureia, respectivamente, foram as que apresentaram a relação de 2:1 entre Ca e P (Tabelas IV e V).

Houve efeito para o teor de $\mathrm{Mg}$ (Tabela V) nas silagens estudadas, tanto na silagem sem adição de ureia, quanto nas silagens com doses crescentes de ureia. Verificou-se decréscimo no teor de Mg nas silagens de sorgo com o capim-marandu e sorgo com capim-mombaça quando acrescidas de ureia. Entretanto, na silagem de sorgo solteiro, foi observado aumento no teor de magnésio em relação ao material antes da ensilagem. Na comparação entre as silagens, verifica-se que a silagem de sorgo com capim-mombaça apresentou os maiores teores de $\mathrm{Mg}$ para todas as doses de ureia avaliadas, resultado este normal pela altura de colheita que incrementa a participação de folhas na massa ensilada e estas apresentam maior teor de clorofila que tem Mg na sua estrutura (Taiz \& Zeiger, 2004).

Sobre os teores de enxofre (Tabela V), observou-se que nas silagens de sorgo consorciado com o capim-marandu e a de sorgo solteiro, houve incremento linear da concentração de $\mathrm{S}$ pelo aumento da dose de ureia. A concentração de enxofre recomendada em dietas de bovinos de corte é de $0,15 \%$ da matéria seca da dieta (NRC, 2000), sendo que apenas as silagens de sorgo consorciado com o capim-marandu e de sorgo solteiro seriam consideradas adequadas para ruminantes com base na recomendação supracitada.

Com base nos dados apresentados, embora seja possível inferir que há influência tanto das espécies vegetais presentes na massa ensilada, quanto da adição de ureia sobre os teores de macronutrientes presentes nas silagens, pela alteração do perfil fermentativo, é importante destacar que, como afirmado por Van Soest (1994) as respostas positivas ou negativas obtidas pela amonização do volumoso são dependentes de diversos fatores, e podem variar de acordo com a umidade do material e as características químicas das plantas, sendo necessários estudos específicos para cada espécie utilizada na produção da silagem.

Segundo Pires et al. (2003), que avaliaram o consumo de silagens de sorgo tratadas com amônia anidra e, ou, sulfeto de sódio na alimentação de novilhas 3/4 Indubrazil/Holandês, a dose de nitrogênio aplicada está em torno de 1,0 a 1,5\% de amônia anidra e de 3,0 a 5,0\% de ureia, com base na matéria seca, quando o 


\begin{tabular}{|c|c|c|c|c|}
\hline \multirow{2}{*}{ Tipos de silagem } & \multicolumn{4}{|c|}{ Doses (\%) } \\
\hline & 0 & 2,5 & 5 & 7,5 \\
\hline \multicolumn{5}{|l|}{$\mathrm{Ca}(\%)$} \\
\hline Sorgo/U. brizantha & 0,27 aA & $0,24 \mathrm{cA}$ & $0,25 \mathrm{bA}$ & $0,27 \mathrm{bA}$ \\
\hline Sorgo/M. maximum & $0,26 \mathrm{aB}$ & $0,32 \mathrm{aA}$ & $0,30 \mathrm{aA}$ & $0,32 \mathrm{aA}$ \\
\hline Sorgo solteiro & $0,27 \mathrm{aB}$ & $0,28 \mathrm{bB}$ & $0,28 \mathrm{abB}$ & $0,34 \mathrm{aA}$ \\
\hline \multicolumn{5}{|l|}{ P-Valor } \\
\hline L & 0,488 & 0,010 & 0,253 & 0,253 \\
\hline Q & 0,505 & 0,000 & 0,003 & 0,000 \\
\hline Eq. de regressão ${ }^{1}$ & 0,2778-0,0050sil & $0,2400+0,0200$ sil & $0,2611+0,0083$ sil & 0,3267-0,0083sil \\
\hline $\mathrm{R}^{2}$ & 51,92 & 25,00 & 10,71 & 6,44 \\
\hline \multicolumn{5}{|l|}{ Mg (\%) } \\
\hline Sorgo/U. brizantha & $0,25 \mathrm{cA}$ & $0,21 \mathrm{cB}$ & $0,23 \mathrm{cAB}$ & $0,22 \mathrm{bB}$ \\
\hline Sorgo/M. maximum & $0,43 \mathrm{bA}$ & $0,42 \mathrm{aA}$ & $0,43 a A$ & $0,36 \mathrm{aB}$ \\
\hline Sorgo solteiro & $0,56 \mathrm{aA}$ & $0,35 \mathrm{bB}$ & $0,34 \mathrm{bB}$ & $0,34 \mathrm{aB}$ \\
\hline \multicolumn{5}{|l|}{ P-Valor } \\
\hline L & 0,000 & 0,000 & 0,000 & 0,063 \\
\hline Q & 0,000 & 0,000 & 0,000 & 0,000 \\
\hline Eq. de regressão ${ }^{1}$ & 0,5422-0,0650sil & $0,2567+0,0350$ sil & $0,2444+0,0433$ sil & $0,2811+0,0117$ sil \\
\hline $\mathrm{R}^{2}$ & 18,24 & 10,71 & 18,67 & 2,30 \\
\hline \multicolumn{5}{|l|}{$\mathrm{S}(\%)$} \\
\hline Sorgo/U. brizantha & $0,11 \mathrm{aD}$ & $0,24 \mathrm{aC}$ & $0,30 \mathrm{aB}$ & $0,37 \mathrm{bA}$ \\
\hline Sorgo/M. maximum & $0,12 \mathrm{aD}$ & $0,15 \mathrm{bC}$ & $0,30 \mathrm{aA}$ & $0,23 \mathrm{cB}$ \\
\hline Sorgo solteiro & $0,11 \mathrm{aD}$ & $0,15 \mathrm{bC}$ & $0,20 \mathrm{bB}$ & 0,43 aA \\
\hline \multicolumn{5}{|l|}{ P-Valor } \\
\hline L & 0,422 & 1,000 & 0,000 & 0,000 \\
\hline Q & 0,355 & 0,000 & 0,000 & 0,000 \\
\hline Eq. de regressão ${ }^{1}$ & $0,1078+0,0033 \mathrm{sil}$ & 0,1800-0,0000sil & $0,1622+0,0517 \mathrm{sil}$ & 0,5478-0,1017sil \\
\hline $\mathrm{R}^{2}$ & 42,86 & - & 75,00 & 95,48 \\
\hline
\end{tabular}

objetivo for conservação. Deve-se adicionar de 2,0 a $4 \%$ de amônia anidra e de 7,0 a $8,0 \%$ de ureia quando o objetivo for a melhoria na qualidade do material com baixa digestibilidade. Já Oliveira, et al. (2007) trataram o capim-tanzânia para fazer ensilagem com quatro doses de ureia $(0 ; 0,25 ; 0,50$ e $0,75 \%$ com base na matéria seca). Entretanto, devido à utilização de doses baixas só observaram resultados positivos no incremento de proteína bruta e aumento na digestibilidade.

Rosa \& Fadel (2001), relatam que a maior eficiência do tratamento com ureia pode ser obtido quando o volumoso possui teor de umidade de $30 \%$ e a ureia é aplicada na dosagem de 4 a $8 \%$ da matéria seca da forragem tratada. Segundo Reis et al. (2006), existem várias razões pelas quais se justifica usar o tratamento químico de volumosos, dentre estas a simplicidade de aplicação da técnica podendo ser adotada tanto pelo pequeno produtor como pelos grandes produtores, auxiliando os mesmos através do aumento da produção dos ruminantes sem ser necessária a aplicação de outros recursos de alimentação de alto custo.

\section{CONCLUSÕES}

A adição de 7,5\% de ureia no material a ser ensilado é eficiente em aumentar o teor de proteína bruta e de enxofre da silagem.

As silagens de sorgo forrageiro consorciado com capim-marandu e capim-mombaça apresentaram maiores teores de proteína bruta, fósforo e potássio que a silagem de sorgo em solteiro sem adição de ureia.

\section{AGRADECIMENTOS}

Ao Conselho Nacional de Desenvolvimento Científico e Tecnológico (CNPq) e à Fundação de Amparo à Pesquisa do Estado de São Paulo (FAPESP) pela concessão de bolsas de graduação (2013/21339-6) e pós- 
graduação (Processo n. 2015/06685-0) para realização dessa pesquisa.

\section{BIBLIOGRAFIA}

Alvares, CA, Stape, JL, Serntelhas, PC, Gonçalves, JLM \& Sparovek, G 2013, 'Köppen's climate classification map for Brazil', Meteorologische Zeitschrift, v. 22, p. 711-728.

Andriguetto, JM \& Perly, L 1990, Nutrição Animal, 4 ed, Nobel, São Paulo. Cantarella, H, Raii, BVan \& Camargo, CEO 1997, 'Adubação de cereais', In: Raii, BVan, Cantarella, H, Quaggio, JA \& Furlani, AMC, 'Recomendações de adubação e calagem para o Estado de São Paulo, 2 ed, Instituto Agronômico, Campinas.

Carvalho, DD, Andrade, JB \& Biondi, P 1992, 'Estádio de maturação na produção e qualidade da silagem de sorgo I: Produção de matéria seca e de proteína bruta', Boletim de Indústria Animal, v.49, p.91-99.

Carvalho, GGP, Pires, AJV, Veloso, CM, Magalhães, AF, Freire, MAL, Silva, FF, Silva, RR \& Carvalho, BMA 2006, 'Valor nutritivo do bagaço de cana-de-açúcar amonizado com quatro doses de ureia', Pesquisa Agropecuária Brasileira, v.41, p. 125-132.

Embrapa, Centro Nacional de Pesquisa dos Solos 2013, 'Sistema brasileiro de classificação de solos', Embrapa/CNPS, Rio de Janeiro.

Fernandes, FEP, Garcia, R, Pires, AJV, Pereira, OG, Carvalho, GGP \& Olivindo, CS 2009, 'Ensilagem de sorgo forrageiro com adição de ureia em dois períodos de armazenamento', Revista Brasileira de Zootecnia, v. 38, n. 11, p. 2111-2115

Getachew, G, Putnam, DH, De Ben, CM \& De Peters, EJ 2016, 'Potential of sorghum as an alternative to corn forage', American Journal of. Plant Sciense, v. 7, p. 1106-1121.

Ítavo, LCV, Ítavo, CCBF, Morais, MG, Coelho, EM \& Dias, AM 2010, 'Composição química e parâmetros fermentativos de silagens de capimelefante e cana-de-açúcar tratadas com aditivos', Revista Brasileira de Saúde e Produção Animal, v.1 1, p.606-617.

Leonel, FP, Pereira, JC, Vieira, RAM, Freitas, JÁ, Dutra, AR, Lima, AV, Ribeiro, MD \& Costa, MG 2006, 'Exigências nutricionais em macronutrientes minerais ( $\mathrm{Ca}, \mathrm{P}, \mathrm{Mg}, \mathrm{Na}$ e K) para novilhos de diferentes grupos genéticos', Revista Brasileira de Zootecnia, v.35, p.584-590.

McDonald, P, Henderson, AR \& Heron, S 1991, 'The biochemistry of silage', 2 ed, Marlow: Chalcombe Publicatins. 340 p.

Malavolta, E, Vitti, GC \& Oliveira, SA 1997, 'Avaliação do estado nutricional das plantas: princípios e aplicações', 2 ed, Associação Brasileira para Pesquisa da Potassa e do Fosfato, Piracicaba.

NRC - National Research Council 2000, 'Nutrient Requirements of Beef Cattle', 7 ed, National Academy Press, Washington, DC.

NRC-National Research Council, 2001, 'NutrientRequirements of Dairy Cattle', 7 ed, National Academy Press, Washington, DC.

Nussio, LG \& Santos, MC 2006, 'Aditivos químicos na ensilagem de cana-de-açúcar', Leite DPA, n. 63, p. 8-12.

Oliveira, HC, Pires, AJV, Oliveira, AC, Rocha Neto, AL, Matos Neto, U, Carvalho, GGP, Veloso, CM \& Oliveira, ULC 2009, 'Perdas e valor nutritivo da silagem de capim-tanzânia amonizado com ureia', Archivos de Zootecnia, v. 58, n. 22, p. 195-202.

Peel, MC, Finlayson, BL \& Macmahon, TA 2007, 'Updated world map of the Köppen-Geiger climate classification', Hydrology and Earth System Sciences, v. 11, p. 1633-1644.

Pires, AJV, Garcia, R, Souza, AL, Silva, FF, Veloso, CM, Cardoso, GC, Oliveira, TN \& Silva, PA 2003, 'Avaliação do consumo de silagens de sorgo tratadas com amônia anidra, e, ou, sulfeto de sódio na alimentação de novilhas $3 / 4$ Indubrazil/Holandês', Revista Brasileira de Zootecnia, v.32, p.1525-1531.

Pires, AJV, Garcia, R, Valadares Filho, SC, Pereira, OG, Cecon, PR, Silva, FF, Silva, PA \& Itavo, LCV 2004, 'Degradabilidade do bagaço de cana-de-açúcar tratado com amônia anidra e, ou, sulfeto de sódio', Revista Brasileira de Zootecnia, v. 33, p.1071-1077.
Raii, B van, Andrade, JC, Cantarella, H \& Quaggio, JA 2001, 'Análise química para avaliação da fertilidade de solos tropicais', Campinas, Instituto Agronômico de Campinas, 285p.

Reis, RA, Teixeira, IAMA \& Siqueira, GR 2006, 'Impacto da qualidade da forragem na produção animal'. paper presented to $43^{a}$ Reunião Anual da Sociedade Brasileira de Zootecnia, João Pessoa: SBZ.

Reis, RA, Rodrigues, LRA, Pereira, JRA \& Ruggieri, AC 2001b, 'Composição química e digestibilidade de fenos tratados com amônia anídra ou ureia', Revista Brasileira de Zootecnia, v.30, p.666-673.

Reis, RA, Rodrigues, LRA, Resende, KT, Pereira, JRA \& Ruggieri, AC 2001 a, 'Avaliação de fontes de amônia para o tratamento de fenos de gramíneas tropicais. II. Compostos nitrogenados', Revista Brasileira de Zootecnia, v.30, p.682-686.

Ribeiro, LSO, Pires, AJV, Carvalho, GGP, Santos, AB, Ferreira, AR, Bonomo, P \& Silva, FF 2010, 'Composição química e perdas fermentativas de silagem de cana-de-açúcar tratada com ureia ou hidroxido de sódio', Revista Brasileira de Zootecnia, v. 39, n. 9, p. 1911-1918.

Rosa, B \& Fadel, R 2001, 'Uso de amônia anidra e de ureia para melhorar o valor alimentício de forragens conservadas'. In: Simpósio sobre produção e utilização de forragens conservadas.', paper presented to UEM/CCA/DZO, Maringá, p. 41-63.

Rylei, JW 1967, 'Silage with urea', In: Briggs, MH, 'Protein supplement'. Oxford: Pergamon Press.

Sarmento, P, Garcia, R, Pires, AJV \& Nascimento A 1999, 'Tratamento do bagaço de cana-de-açúcar com ureia', Revista Brasileira de Zootecnia, v.28, p.1203-1208.

Schmidt, P, Wechsler, FS, Vargas Júnior, FM \& Rossi, P 2003, 'Valor nutritivo do feno de braquiária amonizado com ureia ou inoculado com Pleurotus ostreatus', Revista Brasileira de Zootecnia, v.32 (Suplemento, 2), p. 2040-2049.

Silva, DJ \& Queiroz, AC 2002, 'Análise de alimentos: métodos químicos e biológicos', $3^{a}$ ed. UFV, Viçosa.

Oliveira, AC, Pires, AJV, Oliveira, HC, Patês, NSM, Foncêca, MP, Carvalho, GGP, Neto, UM, Oliveira, ULC, Aguiar, LV \& Oliveira, AB 2007, 'Composição nitrogenada de silagens de gramíneas tropicais tratadas com ureia', Archivos de Zootecnia, v. 56, p. 15- 21.

Silva, GWV, Rocha Júnior, VR, Rocha, WJB, Reis, ST, Pires, DAA, Antunes, APS, Almeida Filho, SHC, Oliveira, LM, Caldeira, LA \& Souza, VM 2014, 'Degradabilidade in situ das silagens de variedades de cana-de-açúcar com aditivos', Archivos de Zootecnia, v.63, n.241, p.171-182.

Taiz, L \& Zeiger, E 2004, 'Fisiologia vegetal', 3.ed. Porto Alegre: Armed, 710p.

Van Soest, PJ 1994, 'Nutritional ecology of the ruminant', 2 ed, Cornell University Press, Ithaca.

Vilela, D 2008, 'Aditivos para silagem de plantas de clima tropical'. In: Reunião anual da sociedade brasileira de zootecnia, 35, Botucatu: SBZ, p.73-108.

Underwood, EJ \& Suttle, NF 2001, 'The mineral nutrition of livestock', 3 ed, Wallingford: CABI Publishing, 614p.

Zambom, MA, Fernandes, T, Soares, MSSP, Castagnara, DD, Neres, MA, Javorski, CR \& Cruz, EA 2014, 'Características da silagem de resíduo úmido de fécula de mandioca adicionada de níveis de ureia', Archivos de Zootecnia, v.63, n.244, p.677-688. 